\title{
Proposta de uma matriz de indicadores de sustentabiliade para avaliação da caprinovinocultura no cariri paraibano através de uma adaptação da metodologia MESMIS
}

Diante da importância econômica que a caprinovinocultura representa para o Nordeste, em especial para as cidades de clima semiárido, esse estudo teve como objetivo elaborar um sistema de indicadores para avaliar a sustentabilidade da caprinovinocultura nos municípios do cariri ocidental paraibano por meio da inclusão do capital social no método MESMIS - Marco para Avaliação de Sistemas de Manejo incorporando Indicadores de Sustentabilidade. A ferramenta metodológica utilizada foi o MESMIS. Trata-se de uma pesquisa exploratória e descritiva em que, para obtenção dos dados para a construção do sistema de indicadores, foi necessário realizar pesquisa de campo através de visitas in loco nas propriedades rurais, acompanhadas de entrevistas semiestruturadas e participação dos caprinovinocultores. Como resultado, verificou-se que a metodologia MESMIS possui uma lacuna em sua concepção por não dar a ênfase necessária ao atributo social, mas apenas aos aspectos relacionados ao meio ambiente e produtividade. Desta forma, foi proposta uma adaptação do método MESMIS com a inclusão do atributo capital social a fim de tornar os resultados mais fidedignos e consistentes para retratar os indicadores do agroecossistema - caprinovinocultura paraibana.

Palavras-chave: Indicadores de sustentabilidade; Caprinovinocultura; MESMIS; Capital Social.

\section{Proposal of a sustainability indicator matrix for the evaluation of caprinovinoculture in Paraiba cariri through an adaptation of the MESMIS methodology}

\begin{abstract}
Given the economic importance that goat farming represents for the Northeast, especially for cities with semi-arid climate, this study aimed to develop a system of indicators to evaluate the sustainability of goat farming in the municipalities of western cariri paraibano through the inclusion of social capital in the MESMIS method - Framework for Evaluation of Management Systems incorporating Sustainability Indicators. The methodological tool used was the MESMIS. This is an exploratory and descriptive research in which, to obtain the data for the construction of the indicator system, it was necessary to carry out field research through on-site visits on the farms, accompanied by semi-structured interviews and participation of goats. As a result, it was found that the MESMIS methodology has a gap in its design by not giving the necessary emphasis to the social attribute, but only to aspects related to the environment and productivity. Thus, it was proposed an adaptation of the MESMIS method with the inclusion of the social capital attribute in order to make the results more reliable and consistent to portray the indicators of Paraiban agroecosystem - caprine livestock.
\end{abstract}

Keywords: Sustainability indicators; Goat breeding; MESMIS; Social capital.

Topic: Desenvolvimento, Sustentabilidade e Meio Ambiente

Reviewed anonymously in the process of blind peer.
Received: 15/06/2019

Approved: 16/07/2019
Robson Fernandes Barbosa (iD

Universidade Federal de Campina Grande, Brasil

http://lattes.cnpq.br/5329317234568143

http://orcid.org/0000-0002-8617-7215

robson rfb@yahoo.com.br

Rafael Albuquerque Xavier

Universidade Federal de Campina Grande, Brasil

http://lattes.cnpq.br/1089099197793431

http://orcid.org/0000-0002-1737-7547

xavierra@uol.com.br
Referencing this:

BARBOSA, R. F.; XAVIER, R. A.. Proposta de uma matriz de indicadores de sustentabiliade para avaliação da caprinovinocultura no cariri paraibano através de uma adaptação da metodologia MESMIS. Revista Ibero-Americana de Ciências Ambientais, v.10, n.4, p.175190, 2019. DOI: http://doi.org/10.6008/CBPC2179-

DOI: 10.6008/CBPC2179-6858.2019.004.0014 


\section{INTRODUÇÃO}

A caprinovinocultura é uma atividade econômica significativa para o Estado da Paraíba e nordeste brasileiro. Segundo o Instituto Brasileiro de Geografia e Estatística (IBGE, 2017) a região Nordeste possui aproximadamente 9 milhões de caprinos e 11,5 milhões de ovinos, correspondendo a, respectivamente, 93\% e 64\% dos rebanhos do País. A Paraíba, especificamente, possui o terceiro maior rebanho de caprino do país, atrás apenas dos estados do Piauí e Ceará com o equivalente a 613.919 cabeças (6,4\% do rebanho do país). Já em relação à quantidade de cabeças de ovinos, ocupa a quarta posição, em que se destacam os estados do Rio Grande do Sul, Ceara e Piauí, respectivamente. Apresentando 572.688 cabeças (3,19\% do rebanho nacional).

As microrregiões do cariri ocidental e oriental paraibano concentram os maiores quantitativos de rebanhos de caprinos e ovinos do estado, segundo os dados preliminares do censo agropecuário do IBGE de 2017, com 330.221 e 163.839 cabeças, respectivamente. Assim, observa-se que a região do cariri ocidental apresenta o dobro de animais em relação ao cariri oriental, o que justifica a escolha dessa microrregião como objeto de estudo. Diante da importância que a caprinovinocultura representa para o estado da Paraíba, é necessário entender como indicadores de sustentabilidade que fortaleça essa cadeia produtiva.

A partir disso, torna-se relevante à existência de instrumentos para simplificar, quantificar e analisar informações perante a medição do progresso sob a ótica da sustentabilidade, auxiliando os pesquisadores no planejamento e desenvolvimento de uma sociedade em base sustentável. Assim, os indicadores de sustentabilidade foram criados para sinalizar sobre um problema antes que ele se torne muito grave e indica o que precisa ser feito para resolvê-lo, evitando que se torne pior e traga danos irreversíveis para a natureza e o homem.

Para Costa (2010), avaliar o desenvolvimento sustentável é um pré-requisito essencial para promover uma agricultura sustentável. Para isso torna-se necessário conhecer as metodologias de avaliação que mostrem explicitamente as vantagens e desvantagens ambientais, sociais e econômicas das diferentes estratégias e sistemas de produção. Conforme Marzall (1999), saber escolher os indicadores que deverão ser medidos para avaliar a sustentabilidade não é tarefa fácil, pois deve ser bem delineado o que se pretende alcançar para escolher os indicadores prioritários para aquele propósito, além dos desafios dos instrumentos de medidas e sua aplicabilidade prática. Portanto, a criação de indicadores para sustentabilidade é um trabalho interdisciplinar e sistêmico que está sempre em transformação.

Neste sentido, a fim de avaliar a sustentabilidade da caprinovinocultura na microrregião do cariri ocidental paraibano, propõe-se utilizar uma adaptação do método MESMIS (Marco para avaliação de Manejo de Recursos Naturais Incorporando Indicadores de Sustentabilidade). Esse sistema representa uma alternativa viável, quando se deseja avaliar e comparar a sustentabilidade de recursos naturais de agroecossistemas nos sistemas de produção agrícola, florestal e/ou pecuária nas dimensões econômicas, sociais e ambientais. 
Proposta de uma matriz de indicadores de sustentabiliade para avaliação da caprinovinocultura no cariri paraibano através de uma adaptação

Mediante a isto, identifica-se uma lacuna na metodologia MESMIS pelo fato de indicadores de cunho social serem menos frequentes, onde este estudo propõe-se a inclusão de mais um atributo (Capital Social) diante dos cinco (Produtividade; Estabilidade, Confiabilidade e Resiliência; Adaptabilidade; Equidade; Autogestão) já existentes com a finalidade de aprimorar a metodologia e trazer resultados mais consistentes e fidedignos.

Masera et al. (1999) esclarece que não existe um conjunto de indicadores que se adequem a todos os agroecossistemas e sendo assim, suas adaptações e melhoria contínua se fazem necessários. Portanto, o atributo capital social atribui um peso decisivamente positivo para o sucesso de experiências de desenvolvimento (PUTNAM, 2002; BECATTINI, 2002). Assim, como objetivo propõe-se elaborar um sistema de indicadores para avaliar a sustentabilidade da caprinovinocultura nos municípios do cariri ocidental paraibano por meio da inclusão do capital social no método MESMIS.

\section{REVISÃO TEÓRICA}

\section{Indicadores de sustentabilidade em agroecossistemas}

A ideia de desenvolver indicadores de sustentabilidade surgiu na Conferência Mundial sobre o Meio Ambiente (Rio-92), conforme registra seu documento final, a Agenda 21. A proposta era definir padrões sustentáveis de desenvolvimento que considerassem aspectos ambientais, econômicos, sociais, éticos e culturais. Para isso, tornou-se necessário definir indicadores que a mensurassem, monitorassem e avaliassem. Um indicador permite a obtenção de informações sobre uma dada realidade (MITCHELL, 1997), podendo sintetizar um conjunto complexo de informações e servir como um instrumento de previsão.

Marzal (1999) chama atenção pela dificuldade em integrar os indicadores na perspectiva da teoria sistêmica e elaborar conjuntos de indicadores levando em conta a sua interdisciplinaridade para a área e a atividade a ser analisada. Entretanto, a preocupação e os esforços realizados com a definição de indicadores de sustentabilidade têm levado a uma percepção mais ampla e, ao mesmo tempo, mais detalhada da realidade. O próprio processo de busca desses indicadores, com os questionamentos que suscita, tem-se evidenciado como um instrumento útil para a melhor compreensão de uma nova concepção de desenvolvimento e das aspirações vitais da humanidade.

Diante do exposto, pode-se afirmar que a construção dos indicadores de sustentabilidade é um ato complexo que deve contemplar a multidisciplinaridade do contexto em questão, cuja elaboração desse sistema de indicadores propiciará o planejamento de políticas para efetivar o processo de desenvolvimento sustentável. É nessa perspectiva que continua a explanação sobre os indicadores de sustentabilidade.

A unidade básica para análise da sustentabilidade é o agroecossistema. De acordo com Toews (1987), agroecossistemas podem ser definidos como "entidades regionais manejadas com o objetivo de produzir alimentos e outros produtos agropecuários, compreendendo as plantas e animais domesticados, elementos bióticos e abióticos do solo, rede de drenagem e de áreas que suportam vegetação natural e vida silvestre. 
Os agroecossistemas incluem de maneira explícita o homem, tanto como produtor como consumidor, tendo, portanto, dimensões socioeconômicas, de saúde pública e ambientais".

Nas atividades agrícolas, a sustentabilidade constitui um novo paradigma que orienta os sistemas produtivos, de modo que eles possam contribuir com o desenvolvimento social, ambiental e econômico da comunidade. Ferreira et al. (2012) afirma que é imperativo a mudança na compreensão do papel do espaço rural na conservação e proteção dos recursos naturais, onde o produtor rural tornou-se protagonista na gestão desses sistemas complexos, diversificados, integrados e interdependentes, na busca por conciliar eficácia econômica, responsabilidade social e proteção do patrimônio natural, tendo como resultado a geração de serviços e produtos para a sociedade.

Para se avaliar a sustentabilidade de um agroecossistema, deve-se considerar suas características hierárquicas e a complementaridade com o ambiente externo. Isso torna possível a identificação dos processos-chaves e dos organismos envolvidos que governam as quatro propriedades ou comportamentos dos agroecossistemas sustentáveis, conforme definidos por Gutierrez et al. (1993) e Conway et al. (1988): produtividade, estabilidade, elasticidade e equidade.

Nessa perspectiva, são constituídos os sistemas para análise da sustentabilidade das atividades agropecuárias, a partir de um conjunto de indicadores que permitem responder as condições atuais da sustentabilidade e orientar as decisões relacionadas ao futuro do agroecossistemas, onde se diferem em termos de composição das variáveis, formas de avaliação, participação dos agricultores ou agentes envolvidos, entre outros.

Masera et al. (1999) esclarece que, apesar de não existir um conjunto de indicadores que se adequem a todos os agroecossistemas, os mesmos devem possuir algumas características em comum, como por exemplo: serem integradores de informações, fáceis de mensurar, úteis para um grande número de agroecossistemas, estarem diretamente ligados à informação de base, permitirem avaliar mudanças durante o tempo, além de serem objetivos e claros. Assim, existem atualmente diversos sistemas para análise da sustentabilidade voltados para as atividades agrícolas, em destaque:

O Método IDEA (Indicadores de Sustentabilidade das Explorações Agrícolas) é mais um sistema de indicadores, desenvolvido na França por Vilain (2000), com o intuito de avaliar a sustentabilidade das práticas agrícolas naquele país. Segundo este autor, trata-se um método simples, de fácil aplicação e interpretação dos resultados, em que visa integrar um conjunto de indicadores na busca por quantificar os vários componentes de um sistema agrícola através da atribuição de uma pontuação numérica e ponderação para agregação das informações nas dimensões agroecológica, socioterritorial e econômica. Portanto, constituise uma ferramenta de avaliação de sustentabilidade e apoio à decisão, identificando os fatores que estão interferindo, de forma positiva ou negativa nas dimensões social, econômica e ambiental.

Desse modo, tem-se destaque as várias aplicações do método IDEA o estudo de Melo et al. (2013), onde avaliou de forma comparativa, os níveis de sustentabilidade existentes nos diferentes sistemas de manejo praticados na agricultura familiar no município de Ceará-Mirim (RN), no qual utilizou 32 indicadores 
de sustentabilidade aplicados a 30 propriedades familiares, sendo divididas em três grupos: "convencionais", "orgânicas" e "agroecológicas".

O ISA (Indicadores de Sustentabilidade em Agroecossistemas) é um sistema integrado para aferição do desempenho econômico, social e ambiental, tendo como objetivo auxiliar na gestão de estabelecimentos rurais. $\mathrm{O}$ sistema é composto por um conjunto de 23 indicadores que abrange os balanços econômico e social, o gerenciamento do estabelecimento, a qualidade do solo e da água, o manejo dos sistemas de produção e a diversificação da paisagem e o estado de conservação da vegetação nativa.

O sistema ISA já foi aplicado em aproximadamente 500 estabelecimentos rurais, em diferentes regiões do estado de Minas Gerais (FERREIRA et al., 2012). Assim, o sistema ISA é apresentado como ferramenta de gestão para o produtor, com o objetivo de realizar um diagnóstico dos balanços social, econômico e ambiental do estabelecimento, apontar pontos críticos ou riscos e os pontos positivos e oportunidades de negócios.

Outra proposta metodológica apresentada é o Índice de Desenvolvimento Sustentável (IDS), ou 'Biograma', desenvolvido na Costa Rica por Sepúlveda (2008), tem como objetivo propor um método que facilite a avaliação de sustentabilidade de projetos e atividades fundamentadas nos princípios do desenvolvimento sustentável. Sepúlveda (2008) esclarece que esta metodologia parte para a construção de indicadores como um instrumento com o qual se pode determinar a sustentabilidade, calculando diversos índices de desenvolvimento, correspondentes a cada dimensão de análise e em cada território rural, que, por fim, integrados, formam o Índice de Desenvolvimento Sustentável relativo a cada território, ou mesmo um só índice para todas as regiões analisadas.

Reis et al. (2013) mostra a utilização da ferramenta biograma proposta por Sepúlveda (2008) para avaliação o desenvolvimento integrado sustentável da produção moderna de bananeira de Ipanguaçu-RN, em que procura identificar dentre 04 agroecossistemas qual o mais sustentável. Assim, o agroecossistema da localidade Olho D'água apareceu como o mais sustentável, estado ótimo, em comparação aos demais. Em contrapartida o plantio da região Base Física mostrou ser o menos sustentável, em estado de colapso. De maneira geral, A água, solo e vegetação nativa - instável.

No entanto, quanto à equidade, no que diz respeito à justa distribuição social e da produtividade entre os agroecossistemas, configura-se um nível de sustentabilidade em estado colapso. Destarte, além desses sistemas de indicadores, existem atualmente outros sistemas com o propósito de analisar a sustentabilidade das atividades agrícolas. Dentre eles, é possível destacar o MESMIS, conforme tratado na sequência.

\section{Método MESMIS}

O MESMIS (Marco para Avaliação de Sistemas de Manejo de Recursos Naturais Incorporando Indicadores de Sustentabilidade) é um sistema criado em 1995 pelo Grupo Interdisciplinar de Tecnologia Rural Apropriada (GIRA) do México servindo como uma ferramenta meramente qualificadora de ações 
sustentáveis que apoia a operacionalização do conceito de sustentabilidade na busca de um desenvolvimento social mais equitativo e ambientalmente saudável nas comunidades rurais.

De acordo com Masera et al. (1999), os criadores do método MEMIS, definem como uma ferramenta que colabora na avaliação da sustentabilidade de manejo de recursos naturais, com ênfase no contexto da agricultura familiar e no âmbito local, buscando entender os fatores limitantes e as possibilidades para a sustentabilidade dos sistemas de manejo que surgem da interseção de processos ambientais com o âmbito social e econômico. O MESMIS é orientado pelas seguintes premissas, onde o conceito de sustentabilidade é definido a partir de cinco atributos gerais, tais como: produtividade; estabilidade, confiabilidade e resiliência; adaptabilidade; equidade; e autogestão, conforme a figura 1.

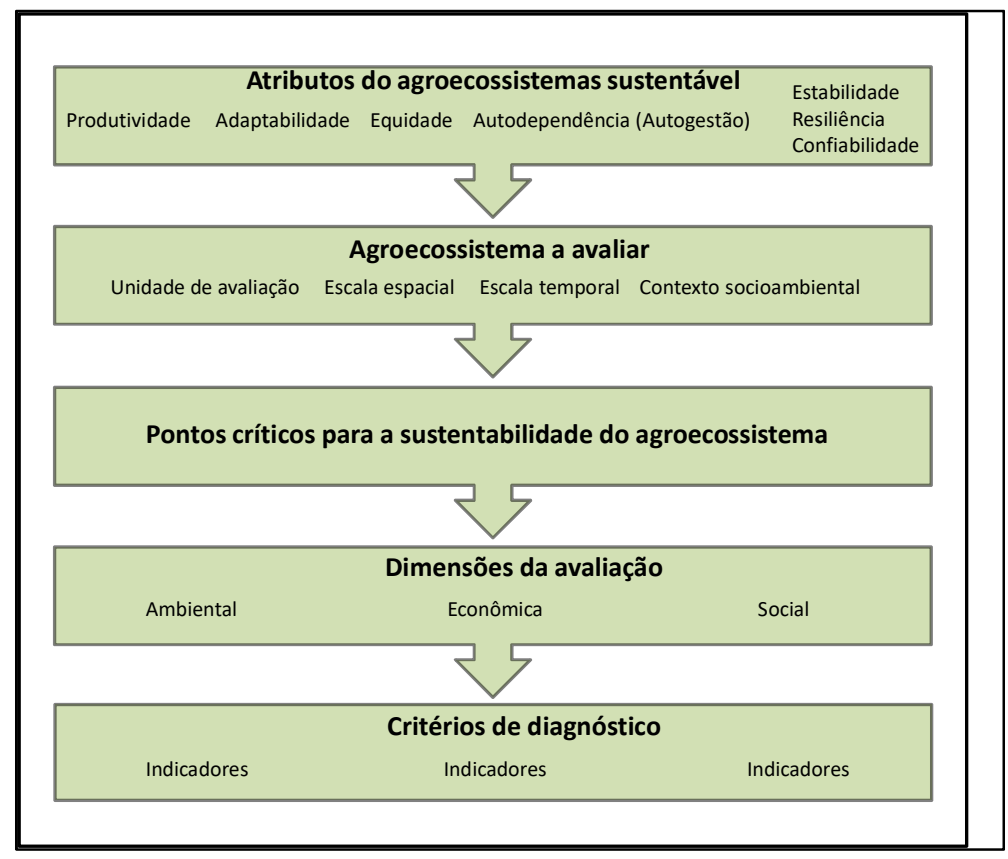

Figura 1: Estrutura do Método MESMIS: relação atributos, dimensões e indicadores de sustentabilidade. Fonte: Masera et al. (1999).

Assim, diante da estrutura do método MESMIS, verifica-se que existe uma integração entre as etapas apresentadas, desde os atributos do agroecossistemas até a criação dos indicadores de sustentabilidade. Os atributos são detalhados segundo Masera et al. (1999): Produtividade: refere-se à quantidade de recursos necessários para se obter um nível de produção em determinado intervalo de tempo. São os ganhos e rendimentos da propriedade agrícola.

Adaptabilidade: é a capacidade do agroecossistema encontrar novos níveis de equilíbrio. É a capacidade de buscar novos níveis estratégicos de produção mediante a demanda imposta. Inclui desde a capacidade de geração de novas tecnologias para melhorar a situação existente até diversificação dos processos da organizacional social, formação de recursos humanos e de aprendizagem; Equidade: é a capacidade do sistema distribuir de maneira justa os benefícios custos e os custos resultante do manejo dos recursos naturais.

Autodependência ou autogestão: é a capacidade do agroecossistema de regular e controlar suas ações com o ambiente externo. Um exemplo de baixa capacidade de autogestão é a necessidade de aquisição 
de fertilizantes do solo de um agroecossistema. Sistemas convencionais ou tradicionais são mais dependentes do que os sistemas alternativos ou ecológicos; Estabilidade: significa a manutenção continuada da produtividade dos agroecossistemas no longo prazo.

Resiliência: é a capacidade do agrossistema retornar ao estado de equilíbrio ou manter o potencial produtivo após a ocorrência de perturbações graves. Ela pode ser observada na capacidade de restabelecer o equilíbrio econômico de uma unidade produtiva após a queda drástica do preço de um produto importante. Confiabilidade: trata-se da capacidade do sistema de manter sua produtividade ou benefícios desejados em níveis próximos ao equilíbrio (sem grandes flutuações na produtividade), mesmo que haja perturbações do ambiente.

Observados esses atributos, é necessário entender como está sistematizado a aplicação da metodologia MESMIS através do seu passo-a-passo. Portanto, através dos atributos constituídos são definidos os pontos críticos (potencialidades e limitações), bem como o seu enquadramento em cada dimensão (social, econômica e ambiental), realizado essas etapas serão estabelecidos os critérios de diagnósticos para a escolha dos indicadores, logo após, é realizado sua medição e monitoramento para em seguida ser integralizado os resultados para as recomendações necessárias. Ver figura 2.

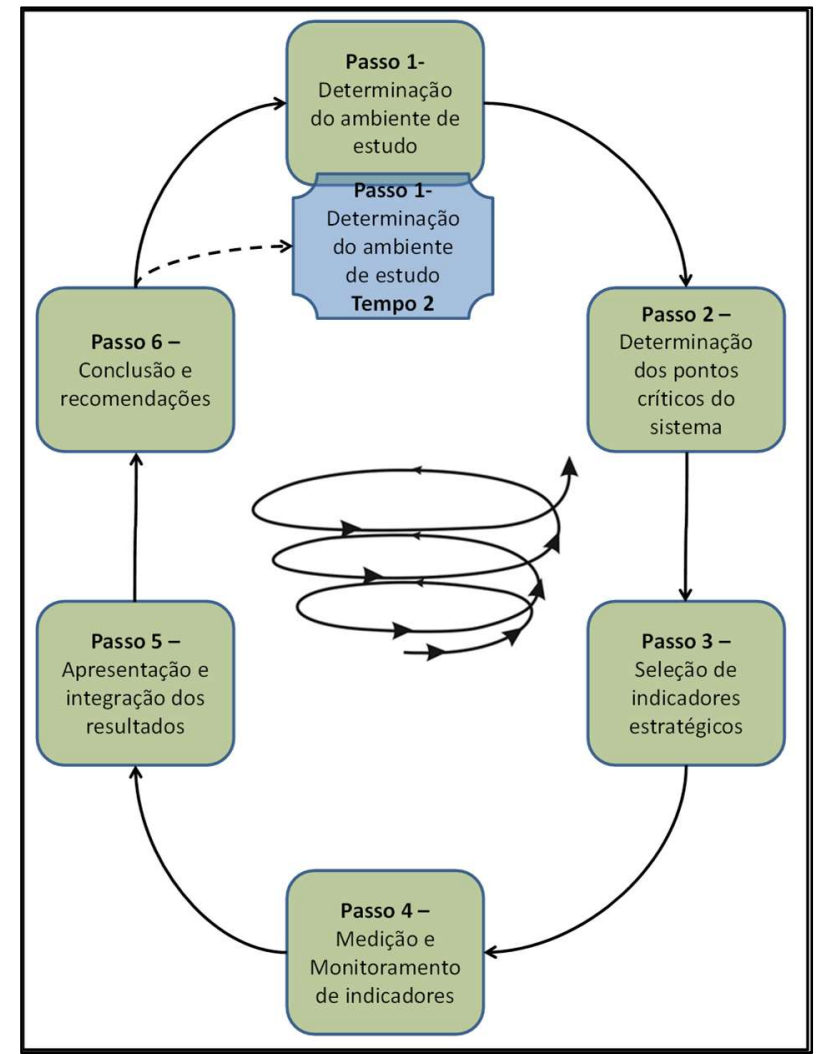

Figura 2: Ciclo de avaliação da sustentabilidade proposto pelo MESMIS. Fonte: Masera et al. (1999).

De maneira mais detalhada cada passo do ciclo de avaliação da sustentabilidade metodologia MESMIS é descrito: Passo 1: é realizado o estudo detalhado dos agroecossistemas da proposta de avaliação, identificando os sistemas de manejo, suas características e contexto socioeconômico e ambiental; Passo 2: se determinam os pontos críticos que podem incidir nos agroecossistemas através das potencialidades e 
Proposta de uma matriz de indicadores de sustentabiliade para avaliação da caprinovinocultura no cariri paraibano através de uma adaptação da metodologia MESMIS

limitações atribuídas a sustentabilidade; Passo 3: ocorre a seleção de indicadores: nesta etapa foram determinados os critérios de diagnósticos, a partir dos quais derivaram os indicadores estratégicos com os quais foram realizadas as avaliações; Passo 4: realiza-se a mensuração dos indicadores através da formulação de instrumentos de avaliação, com o objetivo de obter, quantificar, as informações desejadas, de origem qualitativas e quantitativas.

Passo 5: é onde ocorre a apresentação e integração dos resultados referente à avaliação qualitativa e quantitativa do agroecossistema. É verificado o seu comportamento e para facilitar a visualização dos resultados utilizam-se gráficos tipo radial (ameba); Por fim, passo 6: nesta última etapa são feitas as indicações gerais, um síntese da avaliação e propostas alternativas para fortalecer a sustentabilidade dos sistemas de manejo, assim como para melhorar o processo da própria avaliação em trabalhos futuros na região.

Após a realização desses seis passos torna-se possível obter um melhor entendimento do agroecossistema em estudo, como também é observado o que será necessário ser aprimorado nele. $\mathrm{O}$ que contribui para a elaboração de um redesenha no agroecossistema, segundo os indicadores construídos e monitorados com fins na sustentabilidade.

Sendo assim, por mais que a estrutura do método MESMIS tenha sido pensado para por uma equipe multidisciplinar, deve-se priorizar a apropriação do método pelos agricultores, para que sejam protagonistas do processo. Os indicadores de sustentabilidade demandam um olhar sistêmico e o tratamento de temas e dados dos quais as famílias poderiam não estar acostumadas a lidar (em especial aqueles que extrapolam as questões técnicas agrícolas). Conforme verificou Astier et al. (2012) em trabalho de análise crítica do programa MESMIS, de 25 estudos de caso examinados pela equipe, apenas três foram liderados pelos agricultores ou grupos de agricultores.

Desse modo, sistemas de indicadores voltados para ambientes agrários são mais pertinentes para o direcionamento do estudo que se propõe a realizar. Sendo assim, tem-se uma contribuição significativa do estudo de Santos et al. (2010), em que estabeleceram um conjunto de 25 (vinte e cinco) indicadores de sustentabilidade para criação de caprinos no semiárido sergipano através da metodologia PIER (Pressão/Impacto/Estado/Resposta). Porém, limitou-se apenas a propor os indicadores, não sendo feita sua aplicação e, portanto, não sendo mensurada a sustentabilidade do referido agroecossistema.

Outro estudo recente que merece destaque foi o de Alencar (2018), em que se aplicou a metodologia MESMIS para comparar o coco-anão verde em monocultivo e a produção consorciada no perímetro irrigado das várzeas de Sousa (PB). Os pontos críticos que mais limitaram a sustentabilidade local estiveram relacionados com recursos hídricos e condições econômicas, enquanto os pontos críticos que mais fortaleceram a sustentabilidade estiveram relacionados à qualidade de vida.

Apesar dos autores supracitados terem trabalhado na mesma atividade produtiva desse estudo, não se utilizou do método MESMIS para sua aplicação, mas o estudo recente de Silva (2018) avaliou a sustentabilidade da caprinocultura leiteira nos municípios de São João do Cariri e São José dos Cordeiros, 
Proposta de uma matriz de indicadores de sustentabiliade para avaliação da caprinovinocultura no cariri paraibano através de uma adaptação

estado da Paraíba, fazendo-se o uso da metodologia MESMIS. Na pesquisa foram realizadas visitas em 30 propriedades localizadas nos municípios supracitados, pertencentes à região semiárida paraibana. Observouse que, mesmo diante da escassez hídrica vivenciada pela região nos últimos anos, os municípios têm caminhado em direção da sustentabilidade dos seus agroecossistemas analisados, e que a partir da superação das limitações que se apresentaram em cada categoria analisada, conseguem superar as adversidades.

Alguns estudiosos, como Marzall et al. (2000), criticam que os indicadores são elaborados por instituições de pesquisas, organizações e universidades de acordo com sua leitura e interpretação, não deixando claro sua aplicação imediata por parte de agricultores e/ou técnicos, o que pode comprometer sua operacionalização e consecutivamente comprometer sua avaliação mediante a criação dos indicadores de sustentabilidade.

Desse modo, o MESMIS atua como um balizador para o desenvolvimento sustentável mostrando o direcionamento certo rumo a sustentabilidade das diferentes atividades produtivas voltadas para o manejo de recursos naturais. 0 modelo entende a sustentabilidade como um processo que se constrói a partir de uma visão local coletiva, segundo a cooperação de todos os membros de uma sociedade (ASTIER et al., 2008). Nesse sentido o capital social surge como um impulsionador da sustentabilidade e uma alternativa para o fortalecimento da caprinovinocultura e consequentemente, do desenvolvimento local.

\section{Capital social}

A temática que envolve o capital social é representada por vários conceitos distintos e em sua maioria complementares pelos diferentes teóricos. Em que convergem para uma participação mais atuante da sociedade civil e as instituições representativas, visando através das práticas de cooperação e de decisões democráticas o alcance do desenvolvimento local. Segundo D’Araújo (2010), a respeito de capital social, pode-se dizer que é um dos "conceitos mais importantes e mais controversos nas ciências sociais". A grande subjetividade em torno das limitações teóricas e metodológicas são desafios que vem sendo superados através da construção de uma identidade coletiva, e no qual interfere na maior compreensão e resolução dos dilemas atuais.

O capital social pode ser considerado a argamassa que mantém as instituições em contato entre si e as vincula ao cidadão visando à produção do bem comum. É basicamente a capacidade de uma sociedade de estabelecer laços de confiança interpessoal e redes de cooperação com vistas à produção de bens coletivos. (D'ARAUJO, 2010). Para D’Araujo (2010), um fator crítico para a prosperidade econômica e para o desenvolvimento sustentado é a coesão social.

Numa perspectiva cronológica, D’Araujo (2003) afirma que a primeira a fazer referência à expressão capital social foi Lyda Judson no ano de 1916, incorporando-o para descrever centros comunitários de escolas rurais. Em meados de 80, surgem autores relevantes, destacando elementos novos, tais como que 
Proposta de uma matriz de indicadores de sustentabiliade para avaliação da caprinovinocultura no cariri paraibano através de uma adaptação

enfatizavam como confiança, redes sociais, cooperação, engajamento cívico e coesão social, dentre eles: Pierre Bourdieu, James Coleman e Robert Putnam.

Segundo Bourdieu (1980), o capital social pode ser entendido como redes de relações sociais, em que os indivíduos extraem recursos e vantagens, como um multiplicador das outras formas de capital. Para o autor, o capital social envolve às redes permanentes e próximas de um grupo que asseguram aos seus membros um conjunto de recursos atuais e potenciais, direcionando sua pesquisa para a questão do poder e das desigualdades em diferentes campos.

Na percepção de Coleman $(1984,1990)$, o capital social é um conceito importante para o desenvolvimento econômico, físico e humano e tem condições de alcançar recursos para o bem-estar coletivo, referindo-se ainda a aspectos da estrutura social que facilitam certas ações comuns dos atores dentro da estrutura. Além disto, a sua abordagem procura conciliar o capital social aos aspectos relacionados ao desenvolvimento em um dado espaço geográfico.

Já Putnam (1993) ganhou notoriedade ao lançar seu livro referente intitulado: Comunidade e democracia: A experiência da Itália moderna. No qual buscou entender as disparidades de desenvolvimento entre o norte e o sul da Itália, mostrando a importância da capacidade de associativismo para promoção do desenvolvimento. Segundo Putnam (1993), "capital social refere-se a aspectos da organização social, tais como redes, normas e laços de confiança que facilitam a coordenação e cooperação para benefícios mútuos. Capital social aumenta os benefícios de investimento em capital físico e capital humano". Desse modo, Putnam entende que o capital social é a capacidade que determinada população tem de interagir de forma cooperada a partir de relações de confiança historicamente adquiridas e que valores, crenças e atitudes fortalecem os compromissos sociais e a lealdade dos cidadãos com a sua comunidade.

Como forma de quantificar a temática em questão e não apenas se limitar aos conceitos teóricos o Banco Mundial através do grupo temático sobre Capital Social criou em 2003 o Questionário Integrado para Medir Capital Social (QI-MCS), no intuito de facilitar estudos práticos para mensurar o capital social no qual os primeiros estudos foram realizados em países africanos. Neste sentido, Grootaert et al. (2003), propõe seis dimensões para avaliação do capital social.

Grupos e redes: O capital social ajuda a disseminar informações, reduz o comportamento oportunista e facilita a tomada de decisões coletiva. A eficácia com que o capital social estrutural, na forma de associações e redes, cumpre esse papel, depende de vários aspectos desses grupos, refletindo sua estrutura, sua associatividade, e o modo como funcionam.

Confiança e solidariedade: a confiança é um conceito abstrato, difícil de medir em parte porque pode significar coisas diferentes para pessoas diferentes. A confiança também é observada no contexto de transações específicas, tais como emprestar e tomar emprestado. Baseiam-se nas expectativas e experiências do indivíduo em relação a comportamentos que impliquem confiança. Um aspecto importante disso é quanta assistência as pessoas receberam, ou receberiam, de membros de sua comunidade ou rede, em caso de necessidade. 
Proposta de uma matriz de indicadores de sustentabiliade para avaliação da caprinovinocultura no cariri paraibano através de uma adaptação

Ação coletiva e cooperação: esta categoria investiga se e como os membros do domicílio têm trabalho com outras pessoas em sua comunidade, em projetos conjuntos e/ou como resposta a uma crise. Também considera as consequências do não cumprimento das expectativas em relação à participação. a ação coletiva somente é possível quando há um nível significativo de capital social à disposição na comunidade. (pelo menos até onde a cooperação não é imposta por uma força externa, tal como o governo).

Informação e comunicação: O acesso à informação tem sido reconhecido cada vez mais como fundamental para ajudar as comunidades empobrecidas a terem uma voz mais ativa em assuntos relativos ao seu bem-estar. Esta categoria de questões explora os meios pelos quais os domicílios pobres recebem informações relativas às condições de mercado e serviços públicos, e até onde têm acesso às infraestruturas de comunicação.

Coesão e inclusão social: a seção sobre inclusão abrange desde percepções gerais sobre o sentimento de comunhão e unidade social da comunidade, até experiências com exclusão. Se há alguma divisão na comunidade e, caso haja, quais as características que levam a isso. A informação mais relevante em termos de políticas públicas virá do cruzamento detalhado da presença de exclusão por tipo de serviço com as características tidas como motivo de exclusão; por fim, Autoridade ou capacitação (empowerment) e ação política: autoridade ou capacitação (empowerment) refere-se à expansão dos recursos e capacidades das pessoas em tomar parte, negociar, influenciar, controlar e responsabilizar instituições que afetam suas vidas.

Diante de tais considerações, o capital social incorpora novos padrões interativos de desenvolvimento da população local, mobilizando conhecimentos e partilhando responsabilidades. O capital social na sociedade estaria presente também nas redes que se estabelecem nos movimentos sociais e não apenas entre os indivíduos. Estas redes possibilitariam maior pressão por políticas públicas e por seus resultados, o que levaria ao estabelecimento de regras mais claras no funcionamento do aparelho do Estado e ao estabelecimento de relações de confiança entre os atores envolvidos, fortalecendo assim, a caprinovinocultura do semiárido.

\section{METODOLOGIA}

\section{Caracterização da pesquisa}

A referida pesquisa enquadra-se no que condiz em sua natureza em uma pesquisa aplicada, objetivando a prática da problemática mensuração de sustentabilidade da caprinovinocultura. Assim, a pesquisa aplicada corresponde pela necessidade de busca de resolução de problemas de ordem concreta (VERGARA, 2007).

Quanto aos objetivos, poderá ser classificada como uma pesquisa exploratória, devido ao caráter recente e ainda pouco explorado do tema escolhido, não havendo registros de pesquisa semelhante sobre a avaliação da sustentabilidade voltado para a caprinovinocultura do semiárido. Quanto às técnicas de pesquisas poderá ser classificada como bibliográfica para proporcionar maior compreensão sobre os conceitos e abordagens discutidos sobre caprinovinocultura e indicadores de sustentabilidade. 
Como também poderá ser caracterizada como pesquisa de campo, por meio de entrevistas aos criadores de caprinos e ovinos e visitas in locu nas propriedades rurais. Na relação de fins da pesquisa, a mesma coloca-se enquanto descritiva e metodológica, assim, "Esta tipologia de pesquisa visa expor as características de determinada população ou fenômeno ou o estabelecimento de relações entre variáveis" (SILVA et al., 2001).

Deste modo, utiliza-se enquanto base de construção do conhecimento, uma abordagem interdisciplinar, visando apreensão da complexidade que está inserida no contexto das questões ambientais, sociais, econômicas e institucionais, onde a interdisciplinaridade estende dessa maneira seu campo de intervenção "entre disciplinas científicas" para promover o intercâmbio, inter-relação e articulação entre as disciplinas, saberes e práticas, pela intensidade das trocas entre os especialistas e pelo grau de interação real destas no interior de um mesmo projeto (PHILIPPI JUNIOR, 2000).

A ferramenta metodológica utilizada nessa experiência de monitoramento da sustentabilidade é denominada: Marco para la Evaluación de Sistemas de Manejo de Recursos Naturales incorporando Indicadores de Sustentabilidade - MESMIS, (MASERA et al., 1999). Sendo uma metodologia participativa que objetiva avaliar a sustentabilidade dos sistemas de manejo produtivo, nos agroecossistemas em transição agroecológica, levando em consideração os aspectos ecológicos, sociais e econômicos, valorizando o fator do campesino.

Da mesma forma, Verona (2010) caracteriza o MESMIS como um processo dinâmico, interdisciplinar e multiprofissional, aberto a adaptações, onde as ações são reelaboradas e desenvolvidas em consonância com as necessidades dos agroecossistemas avaliados, sendo essencial a participação ativa dos pesquisadores, extensionistas e agricultores.

\section{Caracterização do espaço da pesquisa}

Delimitou-se enquanto espaço de desenvolvimento da pesquisa o cariri ocidental paraibano por apresentar maior quantidade de municípios, totalizando 17 (Amparo, Assunção, Camalaú, Congo, Coxixola, Livramento, Monteiro, Ouro Velho, Parari, Prata, São João do Tigre, São José dos Cordeiros, São Sebastião do Umbuzeiro, Serra Branca, Sumé, Taperoá e Zabelê). Optou-se por esta microrregião ao invés do Cariri Oriental por apresentar a maior extensão territorial, pujança econômica e maior representatividade/quantidade de criadores e números de caprinos e ovinos.

O cariri ocidental possui uma população estimada em 2015 pelo IBGE em 127.274 habitantes e está dividida em dezessete municípios. Possui uma área total de $6.983,601 \mathrm{~km}^{2}$ e uma extensão territorial de $7.075,10 \mathrm{~km}^{2}$, a população que reside na zona rural corresponde a $37,42 \%$ do total. Na figura 3, pode-se observar a diferença do tamanho territorial e a quantidades de cidades presentes entre as microrregiões do Cariri Ocidental e Oriental do Estado da Paraíba. 


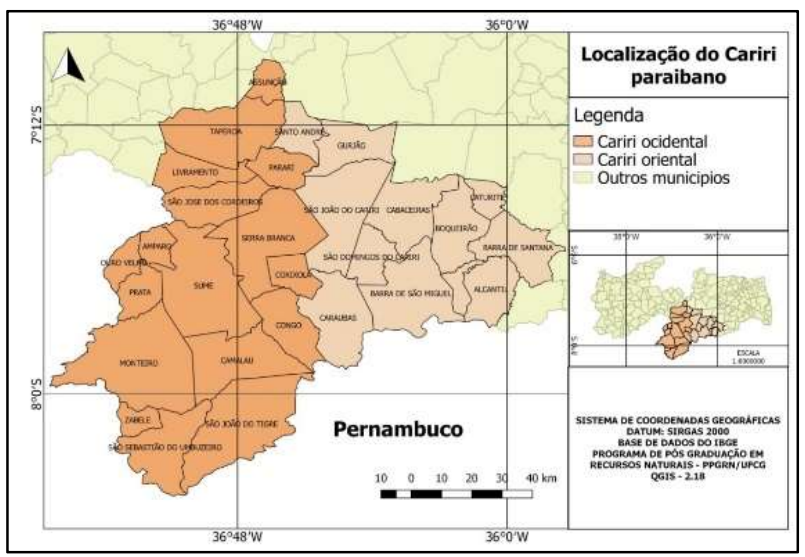

Figura 3: Mapa do Cariri Ocidental.

\section{RESULTADOS}

É crescente a consciência sobre a necessidade de entender o meio ambiente e a manutenção da existência em todas as suas formas com maior complexidade, com atenção à qualidade de vida das pessoas no presente e no futuro, sempre com um foco cultural, ambiental e socioeconômico que qualifique a relação Sociedade-Natureza, considerando que a sustentabilidade ecológica é assegurada por diferentes grupos de agricultores familiares mesmo em situação de vulnerabilidade socioeconômica. Assim, torna-se necessário aprofundar a discussão sobre um 'mundo sustentável' onde as pessoas possam conviver e incorporar diretamente conceitos como 'desenvolvimento sustentável' e 'sustentabilidade', os quais são de importância fundamental nas tomadas de decisões em todos os níveis de organização da sociedade.

Sendo assim, ao se buscar analisar a sustentabilidade do agroecossistemas da caprinovinocultura do cariri paraibano, percebeu-se após as visitas nas propriedades rurais que o atributo capital social é de suma importância para o fortalecimento da cadeia produtiva. Pois, a partir da adaptação do método MESMIS através do incremento capital social, será possível mensurar o nível de sustentabilidade da atividade pecuária, a partir da identificação das potencialidades e vulnerabilidades da atividade, para incorporar as práticas sustentáveis adequadas ao contexto local, como forma de manter seu funcionamento, e ao mesmo tempo contribuir para o desenvolvimento local sustentável.

Os critérios de diagnóstico para analisar o atributo capital social foram escolhidas algumas informações básicas. De acordo com Grootaert et al (2003), são três dimensões úteis para medir o capital social de maneira relevante para as políticas públicas, são eles: grupos e redes; confiança e solidariedade; ação coletiva e cooperação; Informação e comunicação, coesão e inclusão social e; autoridade ou capacitação. Sendo assim, adotou-se essas seis dimensões como critérios de diagnóstico para avaliar o atributo capital social, em que a partir da criação dos indicadores de sustentabilidade voltado para esta temática será possível ter uma visão mais ampla e real do agroecossistema estudado. A figura a seguir mostra como se configura o modelo de avaliação proposto para a caprinovinocultura. Veja a figura 4. 


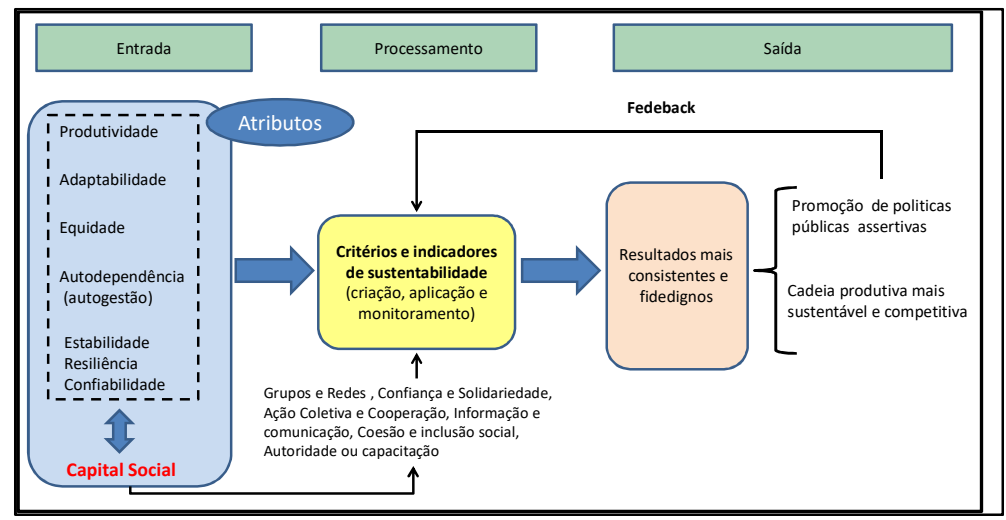

Figura 4: Modelo de avaliação da caprinovinocultura.

Verifica-se no modelo de avaliação da caprinovinocultura que o atributo capital social interage com todos os outros, influenciando para uma maior sinergia entre eles e proporcionando um maior escopo diante da criação de novos indicadores e trazendo resultados mais consistentes e fidedignos, o que pode facilitar na promoção de políticas públicas mais eficientes para o setor e fortalecer a cadeia produtiva com foco na sustentabilidade e competitividade.

Desta forma, acredita-se que o estudo pode contribuir na elaboração e/ou reformulação de políticas públicas voltadas para o desenvolvimento sustentável, a partir da comunicação de seus processos e resultados, a fim de contribuir, de fato, para que o conhecimento gerado seja apropriado por todos aqueles envolvidos no processo, e/ou que tenha interesse na temática.

Diante do modelo estrutural criado, conforme a figura 4, foi elaborado um conjunto de indicadores de sustentabilidade a partir de uma matriz preexistente construída pelo pesquisador e com a ajuda dos caprinovinocultores foram acrescidos e/ou eliminados os indicadores conforme a percepção deles. Após a análise primária dos dados foi selecionado os pontos mais relevantes da atividade produtiva e estabelecidos os pontos críticos para a daí serem criados os indicadores.

Quadro 1: Matriz de indicadores da caprinovinocultura.

\begin{tabular}{|c|c|c|c|}
\hline Atributos & Critério de & Indicadores & $\begin{array}{l}\text { Áreas de } \\
\text { avaliação }\end{array}$ \\
\hline \multirow{4}{*}{ Produtividade } & \multirow[t]{2}{*}{ Rentabilidade } & Renda oriunda da caprinovinocultura & Econômica \\
\hline & & $\begin{array}{l}\text { Rendimento oriunda de atividades agrícolas } \\
\text { (silagem, feno e arredamento de pasto) }\end{array}$ & Econômica \\
\hline & \multirow[t]{2}{*}{ Eficiência } & Relação custos/benefícios com atividade de criação & Econômica \\
\hline & & Prolificidade & Econômica \\
\hline \multirow{7}{*}{$\begin{array}{l}\text { Estabilidade, Resiliência, } \\
\text { Confiabilidade }\end{array}$} & \multirow[t]{3}{*}{ Diversidade } & Diversidade de atividades produtivas exploradas & Econômica \\
\hline & & Diversidade de raças da caprinovinocultura exploradas & Econômica \\
\hline & & Diversidade de espécies de animais exploradas & Econômica \\
\hline & \multirow{4}{*}{$\begin{array}{l}\text { Conservação dos recursos } \\
\text { naturais }\end{array}$} & Contribuição para a degradação física do solo (H/Ha) & Ambiental \\
\hline & & $\begin{array}{l}\text { Há plantio de campineira ou outra cultura voltada para } \\
\text { alimentação animal }\end{array}$ & Ambiental \\
\hline & & Existência da rotação de pastagem & Ambiental \\
\hline & & Utilização de fitofármacos & Ambiental \\
\hline \multirow{4}{*}{ Adaptabilidade } & \multirow{4}{*}{$\begin{array}{l}\text { Capacidade de mudança e } \\
\text { inovação }\end{array}$} & Adoção de novas tecnologias & Social \\
\hline & & Aprimoramento das técnicas de manejo & Social \\
\hline & & Disponibilidade/vontade de mudança & Social \\
\hline & & Capacidade de competição (R/Ha) & Econômica \\
\hline \multirow{5}{*}{ Equidade } & \multirow{3}{*}{$\begin{array}{l}\text { Situação de emprego e } \\
\text { relação de trabalho }\end{array}$} & Número de empregos gerados (Qtde) & Econômica \\
\hline & & Empregos assalariados $\mathrm{x}$ temporários (\%) & Econômica \\
\hline & & Disponibilidade de mão-de-obra & Social \\
\hline & \multirow{2}{*}{$\begin{array}{l}\text { Distribuição de custos e/ou } \\
\text { benefícios }\end{array}$} & Forma e exploração da terra (\% terra própria) & Ambienta \\
\hline & & $\begin{array}{l}\text { Proporção de preço recebido pelo agricultor do preço de } \\
\text { mercado (\%) }\end{array}$ & Econômica \\
\hline
\end{tabular}


Proposta de uma matriz de indicadores de sustentabiliade para avaliação da caprinovinocultura no cariri paraibano através de uma adaptação

\begin{tabular}{|c|c|c|c|}
\hline & & Satisfação de moradia do agricultor e seu cônjuge (\%) & Social \\
\hline & & Satisfação de trabalho do agricultor e seu cônjuge (\%) & Social \\
\hline & & Qualidade de vida (\%) & Social \\
\hline \multirow{3}{*}{ Autogestão } & Participação & $\begin{array}{l}\text { Participação efetiva nas decisões na } \\
\text { associação/cooperativa }\end{array}$ & Social \\
\hline & \multirow[t]{2}{*}{ Organização } & Organização estratégica entre os produtores & Social \\
\hline & & $\begin{array}{l}\text { Organização de eventos culturais no município que faça } \\
\text { alusão a caprinovinocultura }\end{array}$ & Social \\
\hline \multirow{14}{*}{ Capital Social } & \multirow[t]{2}{*}{ Grupos e Redes } & $\begin{array}{l}\text { Existência de feira municipal para comercialização dos } \\
\text { animais }\end{array}$ & Econômica \\
\hline & & $\begin{array}{l}\text { Articulação da cadeia produtiva em favor dos seus } \\
\text { fortalecimentos }\end{array}$ & Social \\
\hline & \multirow[t]{3}{*}{ Confiança e Solidariedade } & Transferência de tecnologias sociais (silagem, fenação etc.) & Social \\
\hline & & $\begin{array}{l}\text { Transação comercial de animais com pagamento a prazo } \\
\text { (\%) }\end{array}$ & Social \\
\hline & & Espirito de união entre os criadores & Social \\
\hline & \multirow[t]{3}{*}{ Ação coletiva e cooperação } & Ajuda mútua entre as propriedades (vacinação, parto etc.) & Social \\
\hline & & Atuação de suporte técnico & Social \\
\hline & & Disponibilidade de crédito & Econômica \\
\hline & \multirow[b]{2}{*}{ Informação e Comunicação } & Informações sobre as atividades do governo e mercados & Social \\
\hline & & $\begin{array}{l}\text { O nível de conhecimento da informação é coletivo ou } \\
\text { domiciliar }\end{array}$ & Social \\
\hline & \multirow{3}{*}{ Coesão e inclusão social } & Há divisão (exclusão) na comunidade & Social \\
\hline & & Presença de conflitos & Social \\
\hline & & $\begin{array}{l}\text { Existência de sociabilidade entre as pessoas da } \\
\text { comunidade }\end{array}$ & Social \\
\hline & Autoridade e Ação Política & $\begin{array}{l}\text { Influência da comunidade/cadeia produtiva nas } \\
\text { instituições públicas e/ou mercados }\end{array}$ & Social \\
\hline
\end{tabular}

Por fim, a matriz de avaliação da sustentabilidade pode ser entendida como uma ferramenta de apoio à decisão que deverá ser monitorada periodicamente a fim de apontar a situação de sustentabilidade da caprinovinocultura do semiárido e proporcionar um estudo comparativo através do monitoramento dos seus indicadores. A partir da inclusão do atributo capital social dentro da metodologia MESMIS, tem-se a premissa que quanto mais presentes forem à incorporação dos princípios de confiança, engajamento cívico e cooperação no processo de avaliação da sustentabilidade da caprinovinocultura, mais fidedigna serão as informações que viabilizarão a atividade pecuária de forma sustentável.

\section{CONSIDERAÇÕES FINAIS}

A pesquisa identificou uma lacuna na metodologia MESMIS pelo fato de indicadores de cunho social serem menos frequentes, onde este estudo propõe-se a inclusão de mais um atributo (Capital Social) diante dos cinco (Produtividade; Estabilidade, Confiabilidade e Resiliência; Adaptabilidade; Equidade; Autogestão) já existentes com a finalidade de aprimorar a metodologia e trazer resultados mais consistentes e fidedignos. Sendo assim, devido a flexibilidade do método MESMIS foi possível criar o conjunto de indicadores voltados para a caprinovinocultura do cariri ocidental paraibano e adaptado para a realidade local, ou seja, estabelecer indicadores esclarecem que não existe um conjunto de indicadores que se adequem a todos os agroecossistemas; suas adaptações e melhoria contínua se fazem necessários. Portanto, o atributo capital social impõe um peso decisivamente positivo para o sucesso de experiências de desenvolvimento.

\section{REFERÊNCIAS}

ALENCAR, I. C. W.. Avaliação da Sustentabilidade dos Agroecossistemas Familiares que Produzem Coco-da-Baía em Monocultivo e Policultivo no Perímetro Irrigado das
Várzeas de Sousa-PB. Tese (Doutorado em Recursos Naturais) - Universidade Federal de Campina Grande, Campina Grande, 2018. 
ASTIER, M.; BARRIOS-GARCIA, L.; GALVÁN-MIYOSHI, Y.; GONZÁLEZ-ESQUIVEL, C. E.; MASERA, O.. Assessing the Sustainability of Small Farmer Natural Resource Management Systems. A Critical Analysis of the MESMIS Program (1995-2010). Ecology \& Society, v.17, n.3, 2012.

ASTIER, M.; MASERA, O.; GALVÁN-MIYOSHI, Y.. Evaluación de Sustentabilidad: Un enfoque dinámico y multidimensional. Valencia: Fundación Instituto de Agricultura Ecológica y Sustentable, 2008.

COLEMAN, J.. Foundations of social theory. Cambridge: The Belknapp press of Harvard University Press, 1984

CONWAY, G. R.; BARBIER, E. B.. After the green revolution. Futures, East Lansing, v.22, p.651-670, 1988.

COSTA, A. A. V. M. R.. Agricultura sustentável III: Indicadores. Revista de Ciências Agrárias, v.33, n.2, p.90-105, 2010.

D'ARAÚJO, M. C. S.. Capital Social. 2 ed. Rio de Janeiro: Jorge Zahar, 2010.

D’ARAÚJO, M. C. S.. Capital Social. Rio de Janeiro: Jorge Zahar, 2003.

FERREIRA, J. M. L.; VIANA, J. H. M.; COSTA, A. M.; SOUSA, D. V.; FONTES, A. A.. Indicadores de Sustentabilidade em Agroecossistemas. Informe Agropecuário, Belo Horizonte, v.33, n.271, p.12-25, 2012.

GROOTAERT C.; NARAYAN, D.; JONES, V. N.; WOOLCOCK, M. Questionário Integrado para Medir Capital Social (QI-MCS). Washington: World Bank., 2003.

GUTIERREZ, E.; BRENES, G.; BALDARES, M.. Consultoria sobre un sistema de indicadores de sostenibilidad de la agricultura y de los recursos naturales para America Latina y el Caribe. San Jose: IICA, 1993

IBGE. Instituto Brasileiro de Geografia e Estatística. Pesquisa Pecuária Municipal. Rio de Janeiro: IBGE, 2017.

MARZAL, K.; ALMEIDA, J.. Indicadores de sustentabilidade para agroecossistemas: Estado da arte, limites e potencialidades de uma nova ferramenta para avaliar o desenvolvimento sustentável. Cadernos de Ciência \& Tecnologia, Brasília, v.17, n.1, p.41-59, 2000.
MASERA, O.; ASTIER, M.; LÓPEZ-RIDAURA, S.

Sustentabilidad $Y$ Manejo de Recursos Naturales: el marco de evaluación MESMIS. Cidade do México: Mundi-Prensa, 1999.

MELO, L. E. L.; CÂNDIDO, A. G.. Sustentabilidade da hortifruticultura familiar do município de Ceará-Mirim (RN) sob a ótica do método IDEA. In: CÂNDIDO, G. A.; SILVA, V. P.. Indicadores de Sustentabilidade em Agroecossistemas: Aplicações em Diversos Tipos de Cultivo e Práticas Agrícolas do Rio Grande do Norte. Natal: IFRN, 2015. p.161-177.

PHILIPPI JUNIOR, A.; TUCCI, C. E. M.; HOGAN, D. J.; NAVEGANTES, R.. Interdisciplinaridade em Ciências Ambientais. São Paulo: Signus, 2000.

PUTNAM, R. D.. Comunidade e Democracia: a experiência da Itália moderna. 2 ed. Rio de Janeiro: FGV, 2002.

PUTNAM, R.. The prosperous community: social capital and public life. The American Prospect, n.13, 1993.

SANTOS, F. R.; SANTOS, M. J. C.; PEDRA, W. N.. Sistema silvipastoril: Indicadores de sustentabilidade para criação de caprinos no semiárido sergipano. Agropecuária Científica no Semi-Árido, v.6, p.1-7, 2010.

SEPÚLVEDA, S. S.. Biograma: metodología para estimar el índice de desarrollo sostenible de territorios. San José: IICA, 2008.

SILVA, L.. Sustentabilidade da caprinocultura na região do agreste paraibano 2018. Dissertação (Mestrado em Recursos Naturais) - Universidade Federal de Campina Grande, Campina Grande, 2018.

TOEWS, D. W.. Agroecosystem health: a framework for implementing sustainability in agriculture. London: Oxford University Press, 1987.

VERONA, L. A. F.. A real sustentabilidade dos modelos de produção da agricultura: Indicadores de sustentabilidade na agricultura. Horticultura Brasileira, v.28, n.2, p.52-66, 2010.

VILAIN, L.. La méthode IDEA: Indicateurs de durabilité des explotations agricoles: Guide d'utilisation. Dijon: Educagri, 2000.

A CBPC - Companhia Brasileira de Produção Científica (CNPJ: 11.221.422/0001-03) detém os direitos materiais desta publicação. Os direitos referem-se à publicação do trabalho em qualquer parte do mundo, incluindo os direitos às renovações, expansões e disseminações da contribuição, bem como outros direitos subsidiários. Todos os trabalhos publicados eletronicamente poderão posteriormente ser publicados em coletâneas impressas sob coordenação da Sustenere Publishing, da Companhia Brasileira de Produção Científica e seus parceiros autorizados. Os (as) autores (as) preservam os direitos autorais, mas não têm permissão para a publicação da contribuição em outro meio, impresso ou digital, em português ou em tradução. 